What made this collaboration unique was exploring the intergenerational element, raising awareness of local services and providing a Kirkwood presence in a school setting. This involved a true multidisciplinary team approach, with input across various disciplines within the hospice. A presentation delivered before the performance was designed to be child-friendly, to prompt questions and discussions as well as raise awareness. Children were supported to share their feelings and reactions and chose to share stories of bereavements they had experienced and memories of loved ones. Many wished to be involved in fundraising for Kirkwood.

We are keen to build on the success of the event, through development of a school young ambassador role, exploring ways of linking in with school as community hubs and supporting the theatre company in research for future performances.

\section{P-243 DRAGONFLY - GROUP WORK WITH GRIEVING FAMILIES}

Rob Nichols, Gemma Purnell. St Richard's Hospice, Worcester, UK

\subsection{6/bmjspcare-2019-HUKNC.265}

Background Dragonfly group is a St Richard's Hospice bereavement group. It supports groups of families over six evenings, two weeks apart. It is run by a small team of staff and volunteers.

Over a number of years, the group has developed an effective way of helping families work through their grief. The core principles are:

- The most basic requirement is to give everyone a safe environment where they can express, articulate, and discuss their grief;

- Initially, allowing children to freely discuss their grief is easier if they are separated from their adult family members;

- Once children feel comfortable expressing their grief, bringing the children and adults together and continuing to provide a safe environment for them to articulate their grief together is beneficial for the whole family;

- Taking time doing too little is better than rushing to do too much.

We have learnt that initially both children and adults are reluctant to discuss or express their grief for fear of upsetting the other. Also, we believe that children learn from others that hiding their grief is a correct response to their feelings, following the death of a loved one.

To address this reluctance the following schedule of evening sessions has developed:

- Week 1 - An initial ice breaker where the families make pizzas together;

- Weeks 2-4 Groups are split into child and adult sessions. Exercises around craft and fun are used to allow the children to describe and discuss their feelings. The adults discuss their feeling within their group with some simple exercises being used to encourage discussion;

- Weeks 5-6 The families are brought back together, where they express and discuss their feelings of grief together in an environment where they feel safe to do so.

\section{P-244 MINDCRAFT: EXPLORING, CREATING AND RE-BUILDING INTERNAL WORLDS OF CHILDREN AND YOUNG PEOPLE THROUGH LOSS}

Jo Marovitch. Peace Hospice Care, Watford, UK

\subsection{6/bmjspcare-2019-HUKNC.266}

Background Mortality statistics and census information suggests approximately 370 parents die in Hertfordshire annually, leaving approximately 650 dependent children. Peer support is widely held to be an important way of helping children manage bereavement. Mindcraft is a group psychosocial programme (through medium of art making and creative activities, games and group support) to empower and support children through grief/loss with high level of emotional wellbeing. The group format is also more cost-effective, reaches wider beneficiaries and is good vehicle for involving parents/ carers simultaneously.

Aims

- To support parents, resourcing them to be available and responsive to their child's grief needs thus minimising the potential long-term health manifestations (Gonclaves Soares, Howe, Matijasevich, Wehrmeister, et al., 2016;. Cuervo Tilson, 2018; World Health Organization, 2015);

- To give children the opportunity to express their feelings within an informal group setting, meeting children with similar experiences and networking.

Method Four weekly sessions, followed by a 'catch up session' - primary school age group, secondary school age group and parent/carer group. Parents/carers completed pre- and postprogramme questionnaires.

Results Nineteen parents/carers and children enrolled. Results from evaluation:

- $73 \%$ of parents reported increase in their confidence levels and felt able to support their children more;

- $80 \%$ of parents reported feeling supported with the bereavement by attending the workshop;

- $73 \%$ of families felt decrease in isolation from attending the workshops.

Quotes:

'I changed my status on Facebook to 'widow'. Seems like a small thing, but it was a big thing for me and now I have strength to acknowledge my situation.'

'P... is on his second week in his own room since my husband died. Just to be able to spread out in your own bed is amazing. The programme has been a major thing for us.'

Conclusion Time-limited sessions can have significant impact on a child's ability to process their grief and lead to positive outcomes. Further programmes are recommended.

\section{P-245 CARE AFTER CARING: SUPPORTING FAMILY CARERS FACING AND FOLLOWING BEREAVEMENT}

Alison Penny. National Bereavement Alliance, London, UK

\subsection{6/bmjspcare-2019-HUKNC.267}

This presentation will share findings and good practice case studies from a recent report from the National Bereavement Alliance and Hospice UK, commissioned by NHS England's Commitment to Carers programme. 
Each year in England, over 500,000 carers face the death of the person they were caring for. Preparing for the death of someone close and dealing with its aftermath is one of the most challenging experiences of life, but as with many challenges, it has the capacity to be profound, fulfilling and enriching. For those who were caring for the person, the 'legacies of caring' (Larkin \& Milne, 2017) bring extra dimensions to bereavement. Whether the carer felt prepared for the death or not, the physical, mental, financial and social strain of caring can have lasting impacts well beyond the death.

This presentation will share good practice and ideas to improve outcomes for bereaved carers. Some of these are things that can be put in place before the death, to improve outcomes in bereavement. Others are ways of improving support after the death to make it more sensitive to the legacies of caring'.

The presentation will set out what we know about carers facing and managing bereavement, and some of the recommendations that have been made to improve support. It will summarise the policy context for supporting former carers as a framework.

Drawing on findings from consultations with former carers and those supporting them, it will lay out a series of six aspirations for local areas and services. If these were in place, we would all be able to say 'we get the right support at the right time, before and after the person we are caring for dies'.

Twelve examples of local good practice in supporting carers facing and following bereavement will be shared.

\section{P-246 EVALUATING THE BENEFITS OF MAKE, DO AND MEND}

Lynsey Lawson. St Mary's Hospice, Ulverston, Cumbria

\subsection{6/bmjspcare-2019-HUKNC.268}

Background In December 2017 St Mary's Hospice made a successful application to the Masonic Charitable Foundation Hospice Bereavement Care programme. This application shared our hope to develop a 'Make, Do and Mend workshop' following an internal audit of referrals into the service. This audit identified that the number of bereaved women who came forward for care and support from us, far outnumbered men. We wanted to reach out to these 'missing men'.

Aims Our project aimed to set up a 'Make, Do and Mend' workshop within our retail warehouse, reaching out to bereaved men and women, those caring for their partner or living with their own life-shortening illness. Workshop participants will work alongside each other on a variety of projects and the essence of the group is not building, but the connections, relationships and support between members.

Method The workshop will be led by an experienced retail manager and bereavement staff and volunteers, and will take place in a fully equipped DIY workshop environment. The workshops will run throughout the year on Wednesday and Saturday mornings and participants will be invited to attend eight sessions. Through the use of the Warwick-Edinburgh Wellbeing Scale (WEMWBS) we will seek to evidence an improvement in participants' wellbeing at the end of the eight week programme.

Results Ten workshops have been completed attended by 50 clients (34 men and 16 women). Through the use of the WEMWBS we have identified significant improvements in all 14 areas of the scale as well as clients narratively reporting improvements such as an 80 year old gentleman stating 'The company and overall community feel of the workshop have helped me greatly. We are all in the same boat and support each another through loss'.

\section{P-247 INNOVATION IN BEREAVEMENT CARE - EVALUATING THE IMPACT OF THE HOSPICE ONLINE SUPPORT GROUP}

Lynsey Lawson. St Mary's Hospice, Cumbria, UK

\subsection{6/bmjspcare-2019-HUKNC.269}

Background One of the many things that have changed in the digital age is the way we grieve. While the bereaved have traditionally visited graves or burial sites to talk to deceased loved ones, some are now turning to digital spaces to continue their bonds with the dead. Grieving is once again becoming a community practice with online groups offering support and validation for mourners. As a hospice we recognise the emerging need for online support and as a result we have created our online support group.

Aims Our online support group aims to create:

- A chance for people to share their grief with other bereaved members without feeling unwelcome or uncomfortable;

- A safe place to post poetry, photographs, journals or articles about their loved one who has died;

- A chance for people to feel less lonely in their grief;

- A place to learn coping skills and the importance of self-care.

Method A secure online support group was created in August 2017. Details of the group were shared at initial assessments as well as on the hospice website and on social media in a hope to reach out to the harder to reach groups. The group is supported by trained bereavement volunteers at set times throughout the week.

Results The online support group has been established for 22 months and currently has 82 members ageing from early twenties to late eighties. A further development is that the group now meet monthly at the hospice for a coffee evening. Satisfaction surveys have been completed with the group with one member reporting, 'The group just works for me. We are all in the same boat and support one another, especially as weekends which I find extremely difficult at times'.

\section{P-248 GRIEF IS AS INDIVIDUAL AS A FINGERPRINT. ONE SIZE DOESN'T FIT ALL!}

Lynsey Lawson. St Mary's Hospice, Cumbria, UK

\subsection{6/bmispcare-2019-HUKNC.270}

Background At St Mary's Hospice we recognise grief is unique and individual to the person, but also to each loss. Grieving experiences are unique and can be experienced in different ways. As a hospice we previously adopted the traditional way of formally supporting people who have been bereaved through telephone or face-to-face appointments, however, many people who are bereaved and consider support, choose not to access these traditional services due to their own individual way of grieving and limited alternative support services. As a hospice we recognised it was time to change and develop in line with emerging needs recognising that one size doesn't fit all. 